\title{
Effects of 1,25-Dihydroxycholecalciferol on Recovery and Resolution of Late Transient Neonatal Hypocalcemia
}

\author{
Jennifer M. Amaral, ${ }^{1}$ Steve Abrams, ${ }^{2}$ Lefkothea Karaviti, ${ }^{1}$ and Siripoom V. McKay ${ }^{1}$ \\ ${ }^{1}$ The Pediatric Endocrinology \& Metabolism Section, Texas Children's Hospital and Baylor College of Medicine, \\ Clinical Care Center, Houston, TX 77030, USA \\ ${ }^{2}$ Neonatology Section, Texas Children's Hospital and Baylor College of Medicine, Clinical Care Center, Houston, TX 77030, USA
}

Correspondence should be addressed to Jennifer M. Amaral, jennifer.amaral@dchstx.org

Received 1 October 2009; Revised 11 December 2009; Accepted 13 February 2010

Academic Editor: Thomas O. Carpenter

Copyright ( $) 2010$ Jennifer M. Amaral et al. This is an open access article distributed under the Creative Commons Attribution License, which permits unrestricted use, distribution, and reproduction in any medium, provided the original work is properly cited.

Background. Late transient neonatal hypocalcemia with hyperphosphatemia is potentially life-threatening. The use of 1.25 dihydroxycholecalciferol in the management of neonatal hypocalcemia is unexplored. Objective. We hypothesized adding 1.25 dihydroxycholecalciferol to intravenous continuous calcium infusion $(\mathrm{CaI})$ will achieve accelerated correction of hypocalcemia. Design/Methods. A controlled double-blind randomized placebo group was organized to compare the addition of 1.25 dihydroxycholecalciferol to $\mathrm{CaI}$ in 3-14 day old neonates presenting with hypocalcemia, hyperphosphatemia and seizures. Ionized calcium and phosphorus were measured to adjust $\mathrm{CaI}$ and maintain eucalcemia. Time to resolution of hypocalcemia was defined as time from starting $\mathrm{CaI}$ to the first ionized calcium of $\geq 1.1 \mathrm{mmol} / \mathrm{L}$. CaI was discontinued when ionized calcium levels were $\geq 1.1 \mathrm{mmol} / \mathrm{L}$ on two measurements and the infant tolerated feeds. Results. Fourteen neonates were studied without statistical difference between groups. Time to correction of hypocalcemia for 1,25 dihydroxycholecalciferol versus placebo was $7.2 \pm 1.9$ versus $11.5 \pm 3.4$ hours respectively $(p=.26)$. The duration of CaI was $15.0 \pm 1.5$ versus $24.8 \pm 4.4$ hours respectively $(p=.012)$. Conclusions. The addition of 1.25 dihydroxycholecalciferol to standard CaI therapy reduced the duration of CaI, but did not reduce the time to correct hypocalcemia in neonates with late transient hypocalcemia.

\section{Introduction}

Late transient neonatal hypocalcemia with hyperphosphatemia is a potentially life-threatening condition first reported in the 1930s. The condition presents between days of life 3-14, typically with tetanic seizures in a previously healthy term neonate [1]. This condition is rarely seen in breast-fed infants and is believed to be associated with a high phosphate load in the formula $[2,3]$. Introduction of formulas with lower phosphate loads has not eliminated the occurrence of transient neonatal hypocalcemia $[1,4-$ 8 ]. This condition continues to be seen with a frequency of 30/10,000 among formula-fed neonates $[2,8]$. The standard treatment of symptomatic neonatal hypocalcemia is intravenous calcium infusion $[8,9]$. Extravasation of intravenous calcium can result in severe tissue necrosis [3]. IV infiltration rates among neonates vary from $57 \%$ to $70 \%$ and extravasation occurs in $11 \%$ to $23 \%$ of reported cases [10-12]. The most common cause of IV infiltration is total parenteral nutrition $(76 \%)$ and calcium $(72 \%)$ [11, 12]. In addition, intravenous calcium has also been associated with cardiac arrhythmias, notably bradycardia. The use of 1,25-Dihydroxyvitamin $\mathrm{D}\left[1,25(\mathrm{OH})_{2}\right.$ Vitamin $\left.\mathrm{D}\right]$ in the management of transient hypocalcemia is less clear [3,9]. $1,25(\mathrm{OH})_{2}$ Vitamin D might reduce the time of correction of hypocalcemia and the duration of intravenous calcium administration by stimulating calcium mobilization from the bones, reducing renal proximal tubular excretion of calcium, and promoting absorption of calcium from the duodenum during hypocalcemia $[9,13,14]$.

To our knowledge there are no controlled studies that have evaluated the effect of adding $1,25(\mathrm{OH})_{2}$ Vitamin $\mathrm{D}$ to intravenous continuous calcium infusion for late transient neonatal hypocalcemia. We hypothesized that the 
addition of $1,25(\mathrm{OH})_{2}$ Vitamin D to standard intravenous continuous calcium infusion would achieve more rapid resolution of hypocalcemia and shorten the duration of intravenous continuous calcium infusion when compared with intravenous continuous calcium infusion alone.

\section{Study Design}

Following approval by the Baylor College of Medicine's Institutional Review Board, subjects were prospectively enrolled in this double-blind, randomized clinical study. Patients were randomized by pharmacy staff and they were the only ones aware of what therapy infants were receiving. Term infants 3-14 days old weighing $\geq 2000$ grams were eligible for the study if they presented with hypocalcemia (ionized calcium $\leq 1.0 \mathrm{mmol} / \mathrm{L}$ or total calcium $\leq 8.0 \mathrm{mg} / \mathrm{dL}$ ), hyperphosphatemia (phosphorus $\geq 6.0$ $\mathrm{mg} / \mathrm{dL}$ ), and seizures. All infants had to demonstrate a normal cardiothymic silhouette on chest radiograph and have no known congenital anomalies. Recruitment occurred at Texas Children's Hospital between February 2004 through April 2005. Patients were excluded if there was any history of anticonvulsant use, subsequent diagnosis of DiGeorge Syndrome by FISH, or confirmed sepsis. Infants were also excluded if the mother had diabetes mellitus or a known disorder of calcium metabolism.

Intravenous calcium levels and other baseline laboratory studies were collected once hypocalcemia was suspected. Informed consent was obtained within 6 hours of admission. Infants were randomized to receive 0.25 micrograms of $1,25(\mathrm{OH})_{2}$ Vitamin D or placebo (saline) daily after intravenous continuous calcium infusion was initiated. Time of correction of hypocalcemia was defined as the time from initiation of intravenous continuous calcium infusion to the first measured ionized calcium level of $\geq 1.1 \mathrm{mmol} / \mathrm{L}$. Duration of intravenous continuous calcium infusion was defined as the time from initiation of intravenous continuous calcium infusion to the time when intravenous continuous calcium infusion was discontinued.

The evaluation, titration, and dosing of intravenous continuous calcium infusion were based on the clinical protocol described below. The following baseline diagnostic studies were collected to evaluate the etiology of hypocalcemia: total calcium, ionized calcium, serum phosphorus, serum magnesium, intact parathyroid hormone, 25(OH) Vitamin D, $1,25(\mathrm{OH})_{2}$ Vitamin D, FISH for DiGeorge Syndrome and AP chest radiograph. Maternal etiologies of hypocalcemia included diabetes, vitamin D deficiency, and hyperparathyroidism. These were evaluated by measuring maternal HbA1C, 25(OH) Vitamin D, 1,25(OH $)_{2}$ Vitamin D, intact parathyroid hormone, serum ionized calcium, phosphorus and magnesium levels. After all diagnostic studies were collected, a bolus of $10 \mathrm{mg}$ of elemental calcium $/ \mathrm{kg}$ was administered intravenously over 30 minutes. Infants were then started on an intravenous continuous calcium infusion of $100 \mathrm{mg}$ elemental calcium $/ \mathrm{kg} /$ day. Ionized serum calcium and phosphorus levels were obtained every 4-6 hours. The intravenous continuous calcium infusion was titrated to maintain ionized serum calcium levels between 1.1$1.2 \mathrm{mmol} / \mathrm{L}$. Hypomagnesemia was corrected if serum magnesium was $\leq 1.5 \mathrm{mg} / \mathrm{dL}$. If serum ionized calcium levels were $\geq 1.2 \mathrm{mmol} / \mathrm{L}$, the intravenous continuous calcium infusion was reduced using the same algorithm in both groups. Infants were started on Similac PM 60/40 (a low phosphate load formula) or breast milk when ionized calcium was $\geq 1.1 \mathrm{mmol} / \mathrm{L}$ and there was no seizure activity within the past 2 hours. Oral calcium was started once infants tolerated their first feeding. Initial dose of oral calcium was $25 \mathrm{mg}$ elemental calcium $/ \mathrm{kg} /$ day given in 4 daily doses (every 6 hours). Two hours after the first oral calcium dose was administered, the intravenous continuous calcium infusion was reduced by an amount corresponding to the oral calcium dose. If the ionized calcium level was $\geq 1.1 \mathrm{mmol} / \mathrm{L}$ on two separate measurements assuring that calcium level had consistently remained stable and the infant tolerated feeds, infants were switched from intravenous to oral calcium dosing. Intravenous continuous calcium infusion was discontinued 2 hours after the switch to full oral dosing. Serum ionized calcium, phosphorus, and total calcium were checked three hours after the intravenous continuous calcium infusion was discontinued. Once intravenous continuous calcium infusion was stopped, serum calcium and phosphorus levels were obtained every 12 hours and $1,25(\mathrm{OH})_{2}$ Vitamin D or placebo daily was changed from intravenous to oral delivery.

\section{Statistical Analysis}

All data in the results section are expressed as mean \pm standard error. Analysis of covariance (ANCOVA) was used to analyze time of correction of hypocalcemia and time to discontinue intravenous continuous calcium infusion. Initial ionized calcium was covariate in the analysis. Students $t$-test was used to analyze the difference in weight, age at seizures, baseline laboratories and maternal laboratories.

\section{Results}

Fourteen formula-fed neonates were studied [7 receiving placebo, 7 receiving $1,25(\mathrm{OH})_{2}$ Vitamin D]. Four infants received less than $4 \mathrm{oz}(120 \mathrm{cc})$ a day of expressed breast milk. The formulas used included Enfamil LIPIL with Iron (9 infants), Similac Advance (3 infants), Enfamil LactoFree LIPIL ( 1 infant), and Similac Isomil Advance ( 1 infant). Ten infants were Hispanic ( 8 male/2 female) and 4 Caucasian (all males). All results are expressed as mean \pm SEM. Baseline data and laboratory tests are summarized in Table 1.

There was no statistical difference between the placebo and $1,25(\mathrm{OH})_{2}$ Vitamin D group with regard to age at first seizure, age of admission, weight, and all baseline tests except phosphorus (Table 1). The placebo group had a higher initial serum phosphorus level $[P=.03$; unpaired $t$-test when compared to $1,25(\mathrm{OH})_{2}$ Vitamin D group]. All maternal diagnostic tests were normal, except 25(OH) Vitamin D which was low (Table 1). 1,25(OH) 2 Vitamin $\mathrm{D}$ was initiated $4.8 \pm 0.5$ hours after starting intravenous continuous calcium infusion due to processing of the study 
TABle 1: Demographics and baseline laboratory tests by treatment group.

\begin{tabular}{|c|c|c|c|c|c|c|c|c|c|c|}
\hline (Units) & $\begin{array}{l}\text { BirthWeight } \\
\quad(\mathrm{kg})\end{array}$ & Age (days) & $\begin{array}{c}\text { Gender } \\
(\mathrm{M} / \mathrm{F})\end{array}$ & $\begin{array}{l}\text { Ethnicity } \\
\text { (Hispanic/ } \\
\text { Caucasian) }\end{array}$ & $\begin{array}{l}\text { Ionized } \\
\text { Calcium } \\
(\mathrm{mmol} / \mathrm{L})\end{array}$ & $\begin{array}{l}\text { Phosphorus } \\
\text { (mg/dL) }\end{array}$ & $\underset{(\mathrm{mg} / \mathrm{dl})}{\mathrm{Mg}}$ & $\begin{array}{l}\text { Intact } \\
\text { PTH } \\
(\mathrm{pg} / \mathrm{mL})\end{array}$ & $\begin{array}{c}25(\mathrm{OH}) \\
\text { Vitamin D } \\
(\mathrm{ng} / \mathrm{mL})\end{array}$ & $\begin{array}{c}1,25(\mathrm{OH})_{2} \\
\text { Vitamin D } \\
(\mathrm{pg} / \mathrm{mL})\end{array}$ \\
\hline Placebo & $4.06 \pm 0.30$ & $5.4 \pm 0.5$ & $6 / 1$ & $6 / 1$ & $0.86 \pm 0.04$ & $10.5 \pm 0.3^{*}$ & $1.3 \pm 0.1$ & $26.0 \pm 4.0$ & $14.2 \pm 2.8$ & $159.4 \pm 31.1$ \\
\hline $\begin{array}{l}1,25\left(\mathrm{OH}_{2}\right) \\
\text { Vitamin D }\end{array}$ & $3.73 \pm 0.21$ & $6.3 \pm 0.4$ & $6 / 1$ & $4 / 3$ & $0.88 \pm 0.02$ & $9.4 \pm 0.2$ & $1.2 \pm 0.1$ & $31.6 \pm 4.7$ & $15.1 \pm 2.8$ & $140.3 \pm 10.7$ \\
\hline Mean & $3.91 \pm 0.16$ & $5.9 \pm 0.3$ & & & $0.87 \pm 0.02$ & $10.0 \pm 0.2$ & $1.2 \pm 0.1$ & $30.0 \pm 3.0$ & $15.0 \pm 2.0$ & $148.0 \pm 14.0$ \\
\hline Mother & & & & $\begin{array}{c}\text { HgAlC } \\
(\%) 5.2 \pm \\
0.4\end{array}$ & $\begin{array}{c}\text { Total } \\
\text { Calcium } \\
(\mathrm{mg} / \mathrm{dl}) \\
9.35 \pm 0.35\end{array}$ & $3.6 \pm 0.2$ & $3.0 \pm 0.8$ & $\begin{array}{c}65.2 \pm \\
16.3\end{array}$ & $15.3 \pm 4.0$ & $36.8 \pm 5.0$ \\
\hline
\end{tabular}

${ }^{*} P=.03$; $t$-test when compared to $1,25(\mathrm{OH})_{2}$ Vitamin $\mathrm{D}$ group Conversion factors:

Phosphorus $\mathrm{mmol} / \mathrm{L}=\mathrm{mg} / \mathrm{dL} \times 0.32$.

Magnesium $\mathrm{mmol} / \mathrm{L}=\mathrm{mg} / \mathrm{dL} \times 0.5$.

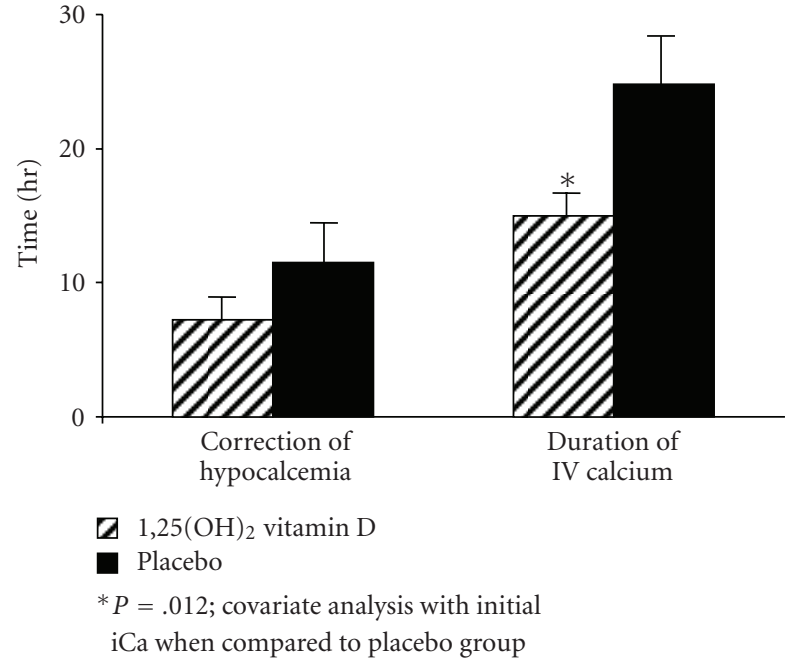

Figure 1: Time to correct hypocalcemia and duration of intravenous calcium infusion by treatment group. (1) Criteria for correction of hypocalcemia: (i) ionized $\mathrm{Ca} \geq 1.1 \mathrm{mmol} / \mathrm{L}$, (ii) seizure free for 2 hours. (2) Criteria for discontinuation of IV calcium: (i) ionized $\mathrm{Ca} \geq 1.1 \mathrm{mmol} / \mathrm{L} \times 2$, (ii) tolerating feeds.

and preparing medication in pharmacy. The time of correction of hypocalcemia for $1,25(\mathrm{OH})_{2}$ Vitamin D group versus placebo was $7.2 \pm 1.9$ versus $11.5 \pm 3.4$ hours, respectively, $(P=.26)$. Duration of intravenous continuous calcium infusion was $15.0 \pm 1.5$ versus $24.8 \pm 4.4$ hours, respectively $(P=.012)$ (Figure 1). Intravenous continuous calcium infusion was not restarted in any of the neonates once it was discontinued. No tissue necrosis or other complications occurred in any of the neonates during the study.

\section{Discussion}

Neonatal hypocalcemia is clinically divided into early and late presentation. Early neonatal hypocalcemia is defined as occurring in the first 48 hours of life. The differential diagnosis includes prematurity, intrauterine growth retardation, and birth asphyxia $[3,9]$. Maternal factors including gestational diabetes, vitamin D deficiency, and hyperparathyroidism can also cause early neonatal hypocalcemia $[3,9$, 15-17]. Late neonatal hypocalcemia is generally defined as hypocalcemia presenting with seizures after the 3rd day of life [18-22]. The differential diagnosis for late neonatal hypocalcemia includes high phosphate load formulas, hypomagnesemia, hypoparathyroidism (including DiGeorge Syndrome), disorders of vitamin D metabolism, bicarbonate infusion, citrate load in transfused blood, lipid infusions, maternal hyperparathyroidism, or any combination of the above $[1-3,9,20-22]$. Our infants were all healthy term infants fed high phosphate formula presenting at the end of the first week of life with hypocalcemia, hyperphosphatemia, hypomagnesemia, and seizures. Almost all reported cases of late transient neonatal hypocalcemia are seen in formula-fed infants (30/10000 compared to $1 / 10000$ in breast-fed infants) [8]. Some authors speculate that the high phosphate load in commercially available formulas combined with immature renal phosphorus excretion and immaturity of the parathyroid hormone response results in a "relative hypoparathyroidism" which is most likely to occur in the first 3 weeks of life resulting in neonatal hypocalcemia $[1,2,4-8,23,24]$.

Late transient neonatal hypocalcemia continues to be reported despite recent reduction in phosphate load in the commercially available formulas $[1,2,4,5,7,8,23]$. Infants presenting with hypocalcemic seizures require intravenous calcium to rapidly correct hypocalcemia [3,9]. Extravasation of intravenous calcium can result in severe tissue necrosis [3]. IV infiltration rates among neonates vary from $57 \%$ to $70 \%$ and extravasation occurs in $11 \%$ to $23 \%$ of reported cases [10-12]. The most common cause of IV infiltration is total parenteral nutrition (76\%) and calcium $(72 \%)[11,12]$.

We postulated that the use of $1,25(\mathrm{OH})_{2}$ Vitamin D in our study population would reduce the time of correction of hypocalcemia. We found that the time to correct hypocalcemia was not statistically different between the placebo and $1,25(\mathrm{OH})_{2}$ Vitamin D treated groups. Due to the delay processing the study and preparing medication in pharmacy, $1,25(\mathrm{OH})_{2}$ Vitamin D was initiated $4.8 \pm 0.5$ hours after 
starting intravenous continuous calcium infusion. Earlier administration of $1,25(\mathrm{OH})_{2}$ Vitamin D might have further reduced the time of resolution of hypocalcemia. The onset of action of $1,25(\mathrm{OH})_{2}$ Vitamin D is approximately 4-6 hours. On average, hypocalcemia was corrected $7.2 \pm 1.9$ hours after intravenous continuous calcium infusion was started and 4.5 hours after $1,25(\mathrm{OH})_{2}$ Vitamin $\mathrm{D}$ was given. There was probably not enough time for the $1,25(\mathrm{OH})_{2}$ Vitamin D to mobilize calcium from the bone. The high dose of intravenous continuous calcium used may also have obscured the effect of $1,25(\mathrm{OH})_{2}$ Vitamin D. The study might have also been underpowered (83\%) due to small sample size.

Once calcium was corrected, $1,25(\mathrm{OH})_{2}$ Vitamin D helped maintaining the ionized calcium concentration above $1.1 \mathrm{mmol} / \mathrm{L}$. This allowed the intravenous continuous calcium infusion to be discontinued 10 hours sooner than in the control group. This 10-hour time difference may reflect the time it takes for $1,25(\mathrm{OH})_{2}$ Vitamin $\mathrm{D}$ to exert its full effect on calcium metabolism. This effect is mediated by $1,25(\mathrm{OH})_{2}$ Vitamin D stimulating calcium mobilization from the bones since promoting calcium absorption from the duodenum and proximal small intestine is mostly vitamin $\mathrm{D}$ independent in neonates $[9,14]$. Reduction of renal proximal tubular excretion of calcium would also be an expected mechanism of action by $1,25(\mathrm{OH})_{2}$ Vitamin D during hypocalcemia along with stimulation of non-genomic pathways involving paracellular calcium absorption due to upregulation of Vitamin D receptor and calcium-sensing receptor $[10,13,25]$.

In conclusion, the addition of $1,25(\mathrm{OH})_{2}$ Vitamin $\mathrm{D}$ to standard intravenous continuous calcium infusion reduced the infusion duration needed to effectively treat late transient neonatal hypocalcemia. A shorter duration of intravenous continuous calcium infusion may reduce the risk of complications associated with intravenous calcium infusion, such as tissue necrosis due to extravasations and could translate to reduced medical cost.

\section{Acknowledgments}

We would like to acknowledge the support and assistance of the endocrine and neonate fellows, nurses, and pediatric residents. We would like to thank Vanessa Bui and the Texas Children's Hospital investigational and neonatal pharmacy staff for preparation of the $1,25(\mathrm{OH})_{2}$ Vitamin $\mathrm{D}$ and placebo.

\section{References}

[1] H. Bakwin, "Pathogenesis of tetany of the new-born," American Journal of Diseases of Children, vol. 54, pp. 1211-1226, 1937.

[2] P. S. Venkataraman, R. C. Tsang, and F. R. Greer, "Late infantile tetany and secondary hyperparathyroidism in infants fed humanized cow milk formula. Longitudinal follow-up," American Journal of Diseases of Children, vol. 139, no. 7, pp. 664-668, 1985.
[3] I. F. Gittleman and J. B. Pincus, "Influence of diet on the occurrence of hyperphosphatemia and hypocalcemia in the newborn infant," Pediatrics, vol. 8, no. 6, pp. 778-787, 1951.

[4] F. Mimouni and R. C. Tsang, "Neonatal hypocalcemia: to treat or not to treat? (A review)," Journal of the American College of Nutrition, vol. 13, no. 5, pp. 408-415, 1994.

[5] L. I. Gardner, E. A. MacLachlan, et al., "Etiologic factors in tetany of newly born infants," Pediatrics, vol. 5, no. 2, pp. 228240, 1950.

[6] W. W. McCrory, C. W. Forman, H. McNamara, et al., "Renal excretion of phosphate in newborn infants: observations in normal infants and infants with hypocalcemic tetany," American Journal of Diseases of Children, vol. 80, pp. 512-513, 1950.

[7] W. Kaplan, L. P. Karaviti, and S. V. McKay, "Hypocalcemia of infancy: effects of formula and ethnicity," International Pediatrics, vol. 20, no. 1, pp. 34-39, 2005.

[8] B. L. Specker, R. C. Tsang, M. L. Ho, T. M. Landi, and T. L. Gratton, "Low serum calcium and high parathyroid hormone levels in neonates fed 'humanized' cow's milk-based formula," American Journal of Diseases of Children, vol. 145, no. 8, pp. 941-945, 1991.

[9] T. O. Carpenter, "Disorders of mineral metabolism in childhood," in Primer on the Mineral Metabolism in Childhood, pp. 349-353, 7th edition, 2008.

[10] Y. Weiss, C. Ackerman, and L. Schmilovitz, "Localized necrosis of scalp in neonates due to calcium gluconate infusions; a cautionary note," Pediatrics, vol. 56, no. 6, pp. 1084-1086, 1975.

[11] L. A. Wynsma, "Negative outcomes of intravascular therapy in infants and children," AACN Clinical Issues, vol. 9, no. 1, pp. 49-63, 1998.

[12] K. L. McCullen and B. Pieper, "A retrospective chart review of risk factors for extravasation among neonates receiving peripheral intravascular fluids," Journal of Wound, Ostomy and Continence Nursing, vol. 33, no. 2, pp. 133-139, 2006.

[13] P. A. Friedman and F. A. Gesek, "Vitamin D3 accelerates PTHdependant calcium transport in distal convoluted tubule cells," American Journal of Physiology, vol. 265, pp. F300-F308, 1993.

[14] R. H. Wasserman and C. S. Fullmer, "Vitamin D and intestinal calcium transport: facts, speculations and hypotheses," Journal of Nutrition, vol. 125, no. 7, supplement, pp. 1971S-1979S, 1995.

[15] P. S. Venkataraman, R. C. Tsang, and J. J. Steichen, "Early neonatal hypocalcemia in extremely preterm infants. High incidence, early onset, and refractoriness to supraphysiologic doses of calcitriol," American Journal of Diseases of Children, vol. 140, no. 10, pp. 1004-1008, 1986.

[16] R. C. Tsang and W. Oh, "Neonatal hypocalcemia in low birth weight infants," Pediatrics, vol. 45, no. 5, pp. 773-781, 1970.

[17] R. C. Tsang, I. Chen, W. Hayes, et al., "Neonatal hypocalcemia in infants with birth asphyxia," Journal of Pediatrics, vol. 84, no. 3, pp. 428-433, 1974.

[18] L. Katz, "Hypocalcemia in infants of diabetic mothers," The Journal of Pediatrics, vol. 81, no. 3, pp. 633-634, 1972.

[19] R. C. Tsang, L. I. Kleinman, J. M. Sutherland, and I. J. Light, "Hypocalcemia in infants of diabetic mothers. Studies in calcium, phosphorus, and magnesium metabolism and parathormone responsiveness," The Journal of Pediatrics, vol. 80, no. 3, pp. 384-395, 1972.

[20] R. C. Tsang, J. J. Steichen, and G. M. Chan, "Neonatal hypocalcemia mechanism of occurrence and management," Critical Care Medicine, vol. 5, no. 1, pp. 56-61, 1977. 
[21] R. Jaafar, N. Yun Boo, R. Rasat, et al., "Neonatal seizures due to maternal primary hyperparathyroidsm," The Journal of Paediatrics and Child Health, vol. 40, no. 5-6, p. 329, 2004.

[22] P. J. Watney, G. W. Chance, P. Scott, and J. M. Thompson, "Maternal factors in neonatal hypocalcaemia: a study in three ethnic groups," British Medical Journal, vol. 2, no. 759, pp. 432-436, 1971.

[23] A. L. Rosenbloom, "Transient congenital idiopathic hypoparathyroidism," Southern Medical Journal, vol. 66, no. 6, pp. 666-670, 1973.

[24] G. T. Lealman, R. W. Logan, J. H. Hutchison, et al., "Calcium, phosphorus, and magnesium concentrations in plasma during first week of life and their relation to type of milk feed," Archives of Disease in Childhood, vol. 51, no. 5, pp. 377-384, 1976.

[25] N. Carrillo-Lopez, D. Alvarez-Hernandez, I. Gonzalez-Suarez, et al., "Simultaneous changer in the calcium-sensing receptor and the vitamin D receptor under the influence of calcium and calcitriol," Nephrology Dialysis Transplantation, vol. 23, no. 11, pp. 3479-3484, 2008. 